\title{
Reproducibility and variability in the assessment of color-coded tissue velocity imaging of the fetal myocardium
}

\author{
Nina Elmstedt ${ }^{1}$, Britta Lind $^{1}$, Kjerstin Ferm-Widlund ${ }^{2}$, Magnus Westgren ${ }^{2}$, Lars-Åke Brodin ${ }^{1}$ \\ 1. Department of Medical Engineering, School of Technology and Health, Royal Institute of Technology, Stockholm, \\ Sweden. 2. Department of Obstetrics and Gynecology, Centre of Fetal Medicine, Karolinska University Hospital Huddinge, \\ Stockholm, Sweden.
}

Correspondence: Nina Elmstedt. Address: Department of Medical Engineering, School of Technology and Health, Royal Institute of Technology, Stockholm, Alfred Nobels Allé 10, Sweden. Email: nina.elmstedt@sth.kth.se.

Received: September 30, 2012 Accepted: January 13, 2012

Online Published: February 21, 2013

DOI : $10.5430 / j b g c . v 3 n 2 p 16$

URL: http://dx.doi.org/10.5430/jbgc.v3n2p16

\section{Abstract}

Objective: The introduction of color-coded tissue velocity imaging (TVI) in fetal medicine is quite recent, and as this method is presently evaluated and developed in regard to diagnostic precision it is of outmost importance to evaluate the reproducibility for adequate clinical use. In this study, reproducibility and intra- and inter-observer variability was assessed for offline analysis as well as echocardiography investigations. Also, we evaluated the importance of exact placement of the region of interest (ROI).

Methods: TVI recordings from 21 fetuses, at a gestational age of 27 to 41 weeks, were acquired at 208-239 frames/s for subsequent offline analysis. All recordings were performed with the transducer positioned to provide an apical four-chamber view and the myocardial velocity data was obtained from basal inferoseptum. The data set was analyzed according to Bland-Altman and reproducibility was expressed as the standard error of a single determination, estimated from duplicate determinations in percentage of the total.

Results: The variation of reproducibility for the echocardiography investigation ranged from $2.0 \%$ to $9.8 \%$. The duration of left ventricular ejection, and the peak velocities of early diastolic filling and atrial contraction being the most robust events measured. The variation of inter-observer variability for the echocardiography investigation ranged from $1.5 \%$ to $8.4 \%$, and the variation of intra- and inter-observer variability for the offline analysis ranged from $1.2 \%$ to $10.4 \%$. Least robust were the events of shortest duration, including isovolumetric contraction and relaxation.

Conclusion: We believe that TVI measurements of the fetal myocardium could be performed in the clinical routine with acceptable reproducibility.

\section{Key words}

Tissue velocity imaging, Tissue Doppler, Fetal myocardium, Clinical reproducibility, Intra- and inter-observer variability, Temporal and velocity measurements 


\section{I ntroduction}

In line with other researchers we believe that it would be of great clinical interest to apply tissue Doppler (TD) echocardiography in fetal diagnostics ${ }^{[1,2]}$. Several studies have reported the feasibility of TD for assessing fetal cardiac function using both spectral TD ${ }^{[3-5]}$ and color-coded tissue velocity imaging (TVI) ${ }^{[2,6-8]}$. The advantage of these methods over conventional echocardiography is their ability to quantify cardiac function by providing detailed regional information about myocardial velocity, displacement and strain pattern ${ }^{[9]}$ - information that in several studies have indicated prenatal pathology ${ }^{[5,6,8,10-14]}$. Various studies also report that pathological conditions affect the duration of the different time intervals during a cardiac cycle, and alter the timing between them. For example, fetal oxygen deprivation is most likely indicated by a prolongation of the isovolumetric phases ${ }^{[15,16]}$. This is in accordance with reported changes of the modified myocardial performance index (Mod-MPI) in the IUGR fetus ${ }^{[17]}$, an index that reflects the relationship between the isovolumetric and ejection time intervals.

TVI facilitates quantitative assessment of myocardial wall motion with high temporal resolution. This is important considering that the short duration of the movements of the myocardial walls require a high sampling rate for the acquisition of proper data ${ }^{[19]}$, an issue that becomes even more important when taking into consideration the high fetal heart rate. The frame rate using spectral TD, however, is lower, and this method also has the disadvantage of overestimating displacement values ${ }^{[18]}$. Moreover, the outcome of spectral TD measurements can be significantly altered by varying offline gain settings, whereas the effect of temporal filtering on TVI measurements is insignificant ${ }^{[18]}$. Altogether, this gives TVI several advantages over spectral TD when considered for the clinical practice. Furthermore, TVI has been suggested to be a more sensitive tool for evaluating fetal cardiac function ${ }^{[5]}$, and proven useful in detecting those IUGR fetuses that are at high risk because of hypoxia ${ }^{[11]}$.

The introduction of TVI in fetal medicine is quite recent, and as this method is presently evaluated and developed in regard to diagnostic precision it is of outmost importance to evaluate the reproducibility for adequate clinical use. Regardless, there have been few studies assessing fetal TVI reproducibility or intra- and inter-observer variability. To our knowledge, these studies have been offline studies and the only variables assessed have been peak systolic velocity ${ }^{[10]}$, peak velocity of early diastolic filling and atrial contraction ${ }^{[8,20]}$, strain and strain rate ${ }^{[21]}$. In this study, reproducibility and intra- and inter-observer variability was assessed for echocardiography investigations as well as offline analysis using TVI including both time and velocity components of a fetal cardiac cycle. Also, we evaluated the importance of exact placement of the region of interest (ROI).

\section{Methods}

The study included 21 fetuses, at a gestational age of 27 to 41 weeks. The indication for the ultrasound investigation varied and 13 women had experienced a normal pregnancy, the other women were investigated due to different complications such as; post-term pregnancy $(\mathrm{n}=1)$, intrauterine growth restriction $(\mathrm{n}=1)$, hypothyroidism $(\mathrm{n}=1)$, dichorionic-diamniotic twin $(n=1)$, pregnancy induced hypertension $(n=2)$, epilepsy $(n=1)$ and multiple sclerosis $(n=1)$.

Nine fetuses were included in the intra- and inter-observer variability evaluation for the offline analysis, six fetuses were included in the reproducibility assessment, and six fetuses were included in the inter-observer variability assessment for the echocardiography investigations. The study was approved by the Regional Ethics committee of Stockholm, Sweden, and all subjects gave their informed consent to participate.

Tissue Doppler echocardiography data was obtained with a GE Vivid-i equipment (GE Vingmed, Horten, Norway), using a 3S-RS transducer. All recordings were performed with the transducer positioned to provide a view of the fetal myocardium equivalent to an apical four-chamber view. The 2D and TVI sector widths were minimized to obtain higher frame rates (208-239 frames/s), and the TVI recordings were stored as cine loops of at least five to 10 consecutive cardiac cycles for offline analysis using EchoPAC (GE Vingmed). Measurements were made from fixed sample points in basal 
inferoseptum during the end of systole in one of the cardiac cycles that was considered presentable. When comparing different heart beats this included that the heart rate was consistent. The ROI was set between 1-3 mm, depending on image characteristics such as thickness of septum and interference from valve motion or fetal/maternal movement.

The peak velocities and durations of the five phases of the longitudinal myocardial velocity profile were measured. This included early diastolic filling, atrial contraction, left ventricular ejection and isovolumetric contraction and relaxation.

To assess reproducibility, recordings of six fetuses were performed by the same echocardiography observer five minutes apart for a subsequent offline analysis, performed by the same offline observer. Inter-observer variability for echocardiography investigations was assessed by analyzing recordings of six fetuses obtained by two different echocardiography observers. To assess intra- and inter-observer variability for offline analysis, data from nine recordings was reanalyzed by the same observer and a second observer.

The data set was analyzed according to Bland and Altman ${ }^{[22]}$ and reproducibility was expressed as the standard error of a single determination, estimated from duplicate determinations in percent of the total mean $=$ error of the mean $(E)$. Calculated according to the equation: $\mathrm{E}=\frac{\mathrm{SD} \times 100}{\mathrm{M} \times \sqrt{2}}$

where SD is the standard deviation of the difference and $\mathrm{M}$ the total mean of the observations.

To test the impact of ROI placement, without inherent variability from the intra- or inter-observer variability tests, the longitudinal velocity profiles from seven adjacent ROIs were compared. A repeated measures ANOVA was applied.

\section{Results}

The variation of reproducibility for the echocardiography investigation ranged from $2.0 \%$ to $9.8 \%$, with the duration of left ventricular ejection, and the peak velocities of early diastolic filling (e') and atrial contraction (a') being the most robust events measured. The intra-observer variability for offline measurements ranged from $1.2 \%$ to $7.4 \%$, with the most robust variables being the duration of left ventricular ejection and peak systolic velocity (s'). The coefficient of variation for the offline inter-observer variability test ranged from $3.0 \%$ to $10.4 \%$. The duration of atrial and isovolumetric contraction being the least robust events measured. For the echocardiography investigations, the inter-observer variability test display more robust results compared to the reproducibility test, where the test was performed by the same echocardiography observer. The coefficient of variation ranging from $1.5 \%$ to $8.4 \%$ and $2.0 \%$ to $9.8 \%$, respectively, the most robust variables were s' and e'. The coefficients of variation are stated in Tables 1 and 2, where Table 1 summarizes the systolic and diastolic peak velocities and Table 2 summarizes the time intervals during a cardiac cycle, for reproducibility as well as the inter- and intra-observer variability tests.

Table 1. Coefficients of variation for the systolic and diastolic peak velocities

\begin{tabular}{lllll}
\hline Variable & $\begin{array}{l}\text { Reproducibility } \\
\text { E (\%) }\end{array}$ & $\begin{array}{l}\text { Inter-observer echocar- } \\
\text { diography E (\%) }\end{array}$ & $\begin{array}{l}\text { Intra-observer offline } \\
\text { analysis E (\%) }\end{array}$ & $\begin{array}{l}\text { Inter-observer offline } \\
\text { analysis E (\%) }\end{array}$ \\
\hline Left ventricular ejection & 4.2 & 1.6 & 1.2 & 5.0 \\
Early diastolic filling & 2.2 & 1.5 & 3.7 & 8.3 \\
Atrial contraction & 2.0 & 3.1 & 1.8 & 3.6 \\
Isovolumetric contraction & 6.6 & 3.0 & 3.4 & 4.4 \\
Isovolumetric relaxation & 9.8 & 8.4 & 7.4 & 8.8 \\
\hline
\end{tabular}

Note. The coefficient of variation = standard error of the mean (E) for reproducibility and intra- and inter-observer variability of the systolic and diastolic peak velocities. 
Table 2. Coefficients of variation for the systolic and diastolic durations

\begin{tabular}{lllll}
\hline Variables & $\begin{array}{l}\text { Reproducibility } \\
\text { E (\%) }\end{array}$ & $\begin{array}{l}\text { Inter-observer echocar- } \\
\text { diography E (\%) }\end{array}$ & $\begin{array}{l}\text { Intra-observer offline } \\
\text { analysis E (\%) }\end{array}$ & $\begin{array}{l}\text { Inter-observer offline } \\
\text { analysis E (\%) }\end{array}$ \\
\hline Left ventricular ejection & 2.0 & 2.3 & 1.3 & 3.0 \\
Early diastolic filling & 5.6 & 4.2 & 2.0 & 6.9 \\
Atrial contraction & 3.0 & 2.9 & 2.4 & 9.6 \\
Isovolumetric contraction & 7.8 & 5.5 & 2.3 & 10.4 \\
Isovolumetric relaxation & 9.3 & 6.5 & 2.9 & 7.7 \\
\hline
\end{tabular}

Note. The coefficient of variation = standard error of the mean (E) for reproducibility and intra- and inter-observer variability of the systolic and diastolic durations.

Bland-Altman plots of the variations of the measured variables from the TVI curves are shown in Figure 1 and 2. Examples of the results for the systolic and diastolic myocardial peak velocities are summarized in Figure 1, and examples of the results for the time intervals during a cardiac cycle are summarized in Figure 2.

There were no significant differences amongst the systolic and diastolic peak velocities or time intervals measured from the different ROIs, except if the ROI was placed outside the myocardium. An example displaying the longitudinal myocardial velocity profiles from 7 adjacent ROIs can be seen in Figure 3. However, the repeated measure ANOVA for the impact of the placement of the ROI indicated that there were greater deviation for the peak velocity measurements compared to the measurements of time intervals.
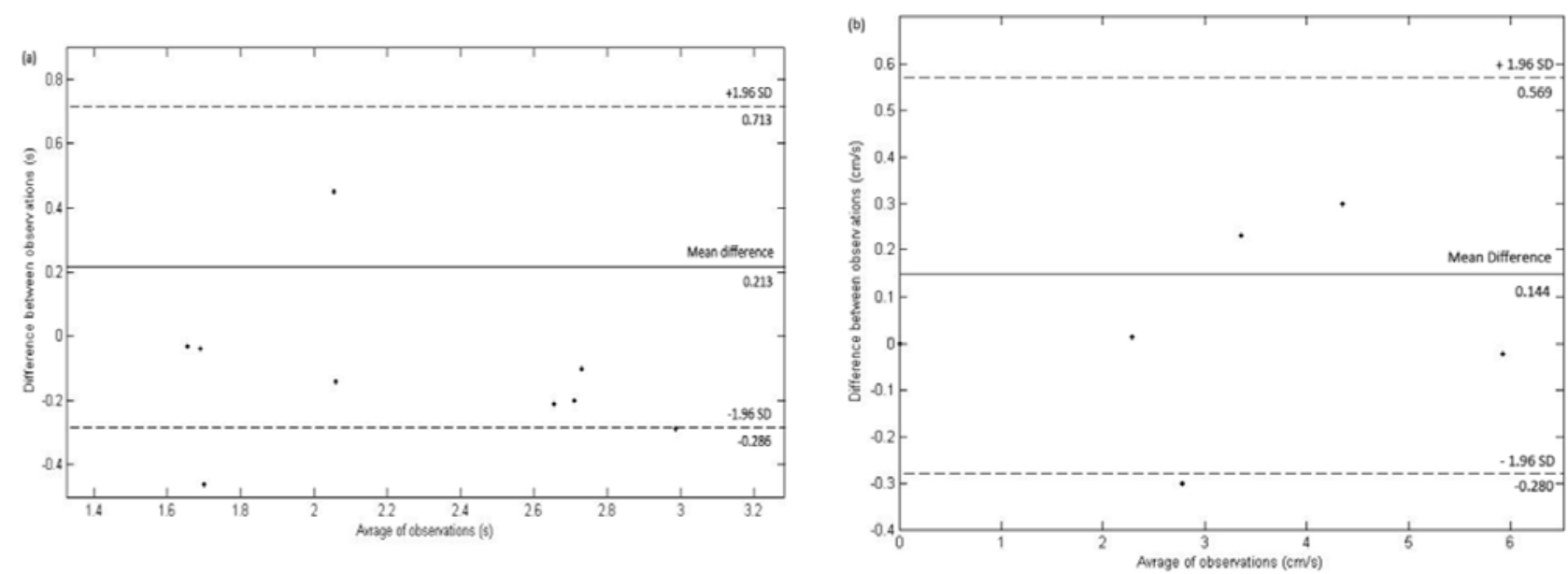

Figure 1. Examples of Bland Altman plots of the variability for the systolic and diastolic peak velocities (a) offline inter-observer variability for peak systolic velocity (s'), (b) reproducibility for the peak velocity of early diastolic filling (e'), and (c) echocardiography investigation inter-observer variability for the peak velocity of isovolumetric contraction.

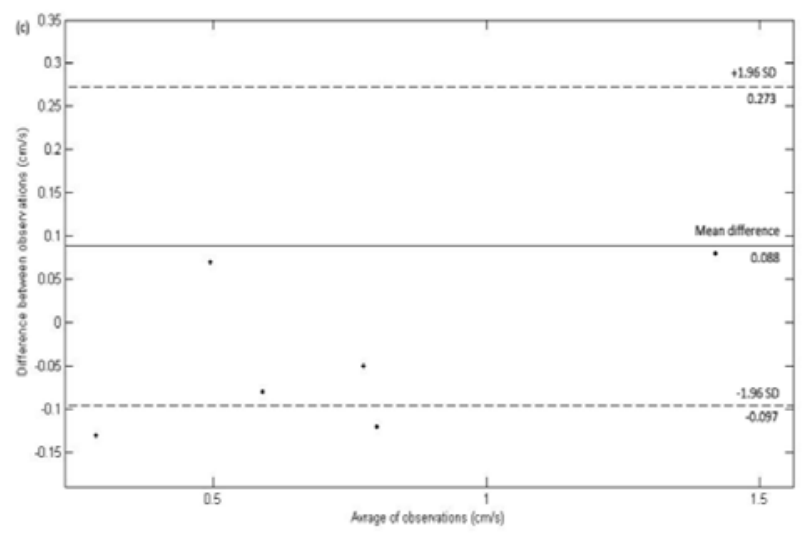



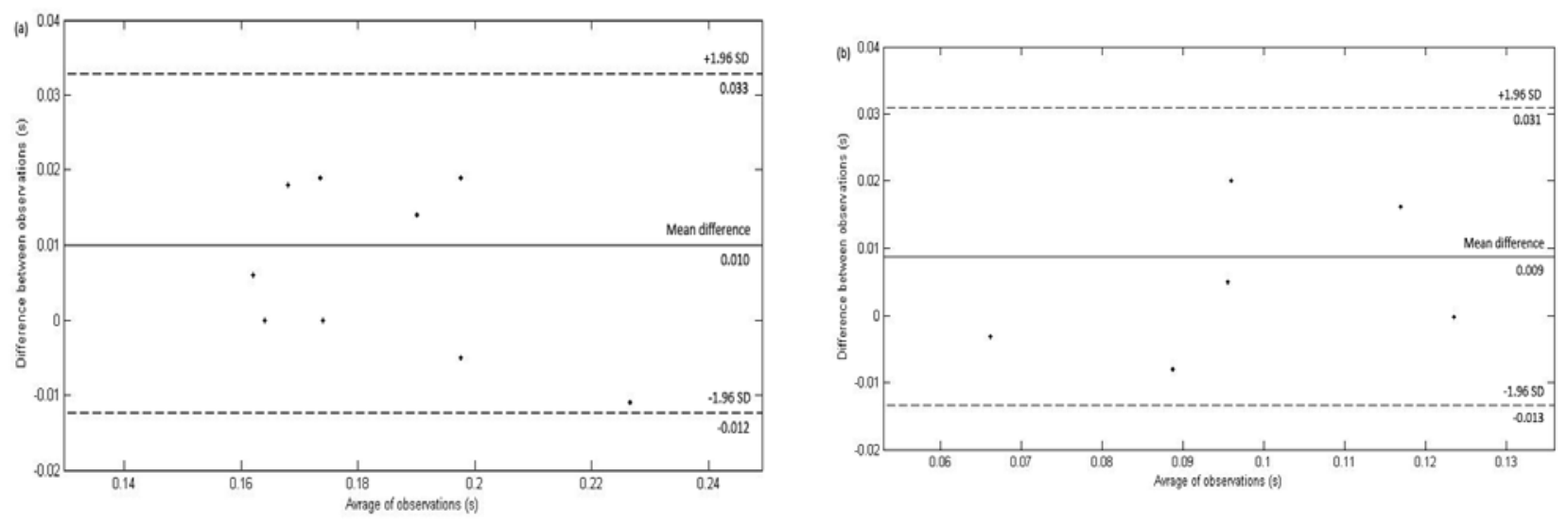

Figure 2. Examples of Bland Altman plots of the variability for the systolic and diastolic durations (a) offline inter-observer variability for the duration of left ventricular ejection, (b) reproducibility for the duration of early diastolic filling, and (c) echocardiography investigation inter-observer variability for the duration of isovolumetric contraction.

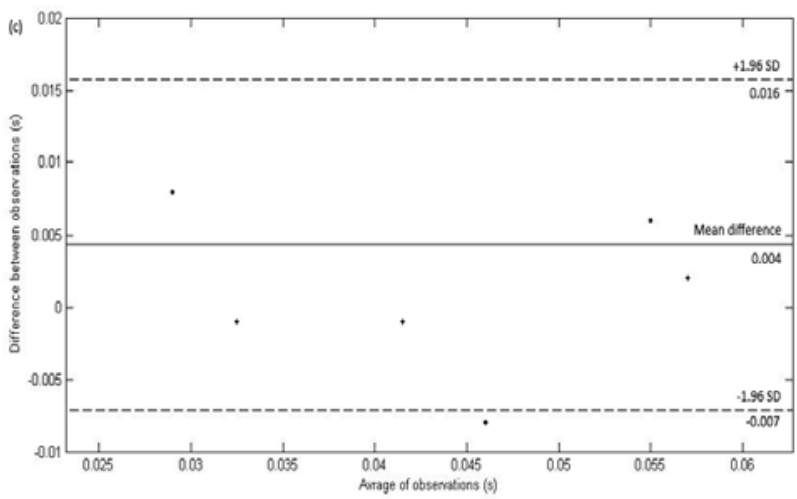

Figure 3. Displaying the longitudinal velocity profiles from 7 adjacent regions of interest (ROI). Myocardial velocity curve and two-dimensional anatomical information were retrieved using the software EchoPAC (GE Vingmed).

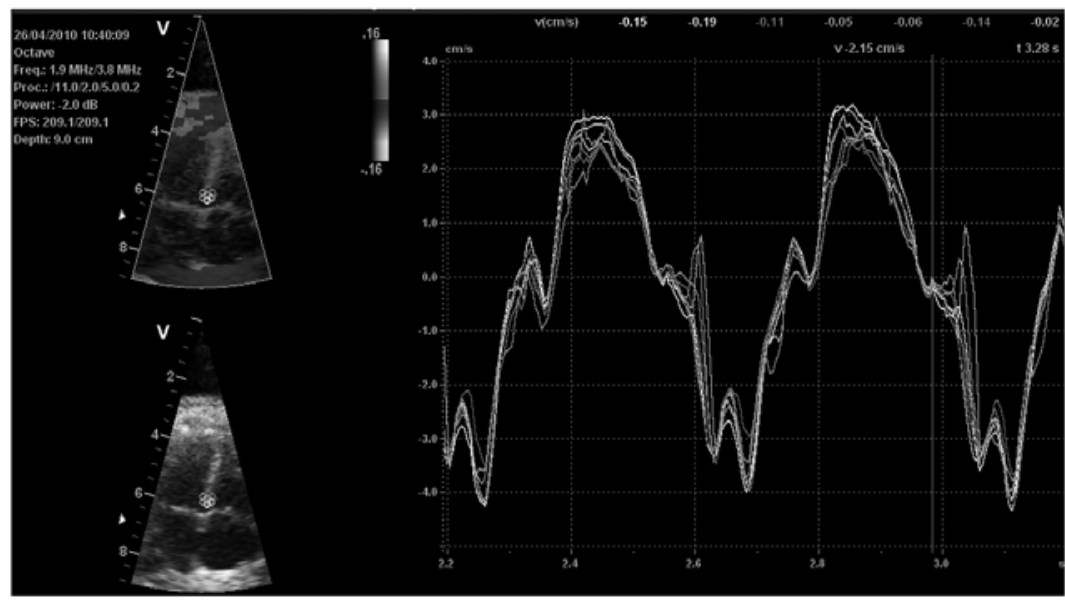

\section{Discussion}

As the use of TVI in fetal diagnostics is presently being evaluated and developed in regard to diagnostic precision, it is of utmost importance that reproducibility is of adequate clinical use. Thus, the aim of this study was to assess reproducibility and intra- and inter-observer variability for offline analysis as well as echocardiography investigations, using this technique. 
The study population included in the present study was small and a mixture of abnormal and normal from different gestational age, but we consider this to be sufficient for the intended purpose. Comparing our results with previous studies evaluating s', e' and a', we show better results for the intra-observer variability than Vogt et al. ${ }^{[20]}$. An explanation for this could be that their study population was larger, but it could also depend on gestational age- a parameter shown by Larsen et al. to affect intra-observer variability of s'-less variability for fetuses $<31$ weeks of gestation ${ }^{[10]}$.

Previous studies have reported observed limitations regarding the occurrence of fetal and/or maternal movement ${ }^{\text {[2, 23-27] }}$ and the importance of exact placement of the ROI for offline analysis ${ }^{[26,27]}$. As far as reproducibility is concerned this creates difficulties when considering the environmental changes between the exams and in placing the ROI in the exact same location between investigations. For example velocity measurements display lower peak velocities when the ROI is placed closer to apex ${ }^{[29]}$, which could explain the distribution of the offline inter-observer variability test for s', shown in Figure 1a. To measure the velocity or time intervals of inferoseptum or the ventricular myocardium, the ROI should be placed above the AV plane ${ }^{[28]}$ in the basal segment ${ }^{[29]}$, and remain in the myocardium during the whole cardiac cycle.

We believed that another challenge would be the considerable variation between heartbeats, however, the results indicate otherwise since better results were achieved evaluating the echocardiography investigations, where heartbeats between different recordings were compared, rather than evaluating the offline inter-observer variability where the same heartbeat was reanalyzed. For the echocardiography investigations, the offline analysis was performed by the same observer, which strengthens the importance of the placement of the ROI.

For the echocardiography investigation, two thirds of the measured variables showed better results for inter-observer variability than for reproducibility. Not expected, since the echocardiography investigation for the reproducibility test, unlike the inter-observer variability test, was performed by the same observer, shown in Tables 1 and 2. Apart from the biological variation, a possible explanation for this could be that the situation of investigation might have a stressing effect on the fetus. For the reproducibility test there were five minutes between the first and second recording whereas between the recordings for the inter-observer variability test the time was no longer than the time it took changing observer.

Taking these observations into consideration, together with the biological variation and the fact that you will never be able to measure the exact same location between investigations - the most important will be to maintain a four chamber view of the fetal myocardium during the ultrasound investigations and carefully place the ROI during the offline analysis. Nevertheless, we demonstrate that temporal and velocity measurements of the fetal myocardium could be performed with acceptable reproducibility in the controlled clinical setting. Although, further studies remain to determine the reproducibility for the clinical routine, we believe that this technique can contribute in the evaluation of myocardial function and dysfunction.

\section{Acknowledgement}

The authors would like to thank Elle Wågström at the Department of Obstetrics and Gynecology, Centre for Fetal Medicine, Karolinska University Hospital Huddinge, for contributing with fetal echocardiography recordings included in the inter-observer variability study for the echocardiography investigations. This work was supported by the Swedish Heart-Lung Foundation.

\section{References}

[1] Steinhard J, Heinig J, Schmitz R, Breithardt OA, Kiesel L, Klockenbusch W. [Tissue Doppler imaging of the fetal heart--a new parametric ultrasound technique in prenatal medicine]. Ultraschall Med. 2007; 28(6): 578-83. PMid:18008214 http://dx.doi.org/10.1055/s-2007-963643 
[2] Larsen LU, Petersen OB, Norrild K, Sorensen K, Uldbjerg N, Sloth E. Strain rate derived from color Doppler myocardial imaging for assessment of fetal cardiac function. Ultrasound Obstet Gynecol. 2006; 27(2): 210-3. PMid:16435318 http://dx.doi.org/10.1002/uog.2669

[3] Nii M, Roman KS, Kingdom J, Redington AN, Jaeggi ET. Assessment of the evolution of normal fetal diastolic function during mid and late gestation by spectral Doppler tissue echocardiography. J Am Soc Echocardiogr. 2006; 19(12): 1431-7. PMid:17138025 http://dx.doi.org/10.1016/j.echo.2006.05.027

[4] Comas M, Crispi F, Gomez O, Puerto B, Figueras F, Gratacos E. Gestational age- and estimated fetal weight-adjusted reference ranges for myocardial tissue Doppler indices at 24-41 weeks' gestation. Ultrasound Obstet Gynecol. 2011; 37(1): 57-64. PMid:21046540 http://dx.doi.org/10.1002/uog.8870

[5] Comas M, Crispi F, Cruz-Martinez R, Martinez JM, Figueras F, Gratacos E. Usefulness of myocardial tissue Doppler vs conventional echocardiography in the evaluation of cardiac dysfunction in early-onset intrauterine growth restriction. Am J Obstet Gynecol. 2010; 203(1): 45 e1-7.

[6] Watanabe S, Hashimoto I, Saito K, et al. Characterization of ventricular myocardial performance in the fetus by tissue Doppler imaging. Circ J. 2009; 73(5): 943-7. PMid:19276611 http://dx.doi.org/10.1253/circj.CJ-08-0529

[7] Yang Y, Li RJ, Li ZA, Song L, Wang Z. Regional atrial myocardial velocity in normal fetuses: evaluation by quantitative tissue velocity imaging. Echocardiography. 2012; 29(2): 182-6. PMid:22066930 http://dx.doi.org/10.1111/j.1540-8175.2011.01562.x

[8] Larsen LU, Petersen OB, Sloth E, Uldbjerg N. Color Doppler myocardial imaging demonstrates reduced diastolic tissue velocity in growth retarded fetuses with flow redistribution. Eur J Obstet Gynecol Reprod Biol. 2011; 155(2): 140-5. PMid:21256662 http://dx.doi.org/10.1016/j.ejogrb.2010.12.020

[9] Martensson M, Bjallmark A, Brodin LA. Evaluation of tissue Doppler-based velocity and deformation imaging: a phantom study of ultrasound systems. Eur J Echocardiogr. 2011; 12(6): 467-76. PMid:21565867 http://dx.doi.org/10.1093/ejechocard/jer056

[10] Larsen LU, Sloth E, Petersen OB, Pedersen TF, Sorensen K, Uldbjerg N. Systolic myocardial velocity alterations in the growthrestricted fetus with cerebroplacental redistribution. Ultrasound Obstet Gynecol. 2009; 34(1): 62-7. PMid:19489024 http://dx.doi.org/10.1002/uog.6375

[11] Botsis D, Vrachnis N, Christodoulakos G. Doppler assessment of the intrauterine growth-restricted fetus. Ann N Y Acad Sci. 2006; 1092: 297-303. PMid:17308154 http://dx.doi.org/10.1196/annals.1365.027

[12] Hatem MA, Zielinsky P, Hatem DM, et al. Assessment of diastolic ventricular function in fetuses of diabetic mothers using tissue Doppler. Cardiol Young. 2008; 18(3): 297-302. PMid:18405423

[13] Divanovic A, Cnota J, Ittenbach R, et al. Characterization of diastolic dysfunction in twin-twin transfusion syndrome: association between Doppler findings and ventricular hypertrophy. J Am Soc Echocardiogr. 2011; 24(8): 834-40. PMid:21641772 http://dx.doi.org/10.1016/j.echo.2011.04.010

[14] Comas M, Crispi F, Cruz-Martinez R, Figueras F, Gratacos E. Tissue Doppler echocardiographic markers of cardiac dysfunction in small-for-gestational age fetuses. Am J Obstet Gynecol. 2011; 205(1): 57 e1-6.

[15] Yumoto Y, Satoh S, Fujita Y, Koga T, Kinukawa N, Nakano H. Noninvasive measurement of isovolumetric contraction time during hypoxemia and acidemia: Fetal lamb validation as an index of cardiac contractility. Early Hum Dev. 2005; 81(7): 635-42. PMid:15970405 http://dx.doi.org/10.1016/j.earlhumdev.2005.04.004

[16] Satoh S, Yumoto Y, Fujita Y, Kinukawa N, Nakano H. Noninvasive measurement of isovolumetric contraction time by Doppler cardiography can be substituted for fetal cardiac contractility: evaluation of a fetal lamb study. Early Hum Dev. 2007; 83(4): $263-7$. PMid:16860948 http://dx.doi.org/10.1016/j.earlhumdev.2006.06.001

[17] Kaponis A, Harada T, Makrydimas G, et al. The importance of venous doppler velocimetry for evaluation of intrauterine growth restriction. Journal of Ultrasound in Medicine. 2011; 30(4): 529-545. PMid:21460154

[18] Manouras A, Shahgaldi K, Winter R, Brodin LA, Nowak J. Measurements of left ventricular myocardial longitudinal systolic displacement using spectral and colour tissue Doppler: time for a reassessment? Cardiovasc Ultrasound. 2009 ; 7: 12. PMid:19292894 http://dx.doi.org/10.1186/1476-7120-7-12

[19] Elmstedt N, Lind B, Ferm-Widlund K, Westgren M, Brodin LA. Temporal frequency requirements for tissue velocity imaging of the fetal heart. Ultrasound Obstet Gynecol. 2011; 38(4): 413-7. PMid:21936002 http://dx.doi.org/10.1002/uog.8872

[20] Vogt M, Muller J, Elmenhorst J, Muhlbauer F, Oberhoffer R. Fetal color-coded tissue Doppler echocardiography: experiences with the "tracking method" in normal fetuses. Eur J Obstet Gynecol Reprod Biol. 2012; 164(1): 10-4. PMid:22656331 http://dx.doi.org/10.1016/j.ejogrb.2012.05.013

[21] Crispi F, Sepulveda-Swatson E, Cruz-Lemini M, et al. Feasibility and Reproducibility of a Standard Protocol for 2D Speckle Tracking and Tissue Doppler-Based Strain and Strain Rate Analysis of the Fetal Heart. Fetal Diagn Ther. 2012; 32(1-2): 96-108. PMid:22722425 http://dx.doi.org/10.1159/000337329 
[22] Bland JM, Altman DG. Statistical methods for assessing agreement between two methods of clinical measurement. Lancet. 1986; 1(8476): 307-10. http://dx.doi.org/10.1016/S0140-6736(86)90837-8

[23] Paladini D, Lamberti A, Teodoro A, Arienzo M, Tartaglione A, Martinelli P. Tissue Doppler imaging of the fetal heart. Ultrasound Obstet Gynecol. 2000; 16(6): 530-5. PMid:11169346 http://dx.doi.org/10.1046/j.1469-0705.2000.00251.x

[24] Jamjureeruk V. Evaluation of ventricular myocardial velocities and heart motion of the fetal heart by tissue Doppler image. J Med Assoc Thai. 2001; 84(8): 1158-63. PMid:11758853

[25] Di Salvo G, Russo MG, Paladini D, et al. Two-dimensional strain to assess regional left and right ventricular longitudinal function in 100 normal foetuses. Eur J Echocardiogr. 2008; 9(6): 754-6. PMid:18490298 http://dx.doi.org/10.1093/ejechocard/jen134

[26] Hernandez-Andrade E, Figueroa-Diesel H, Kottman C, et al. Gestational-age-adjusted reference values for the modified myocardial performance index for evaluation of fetal left cardiac function. Ultrasound Obstet Gynecol. 2007; 29(3): 321-5. PMid:17290412 http://dx.doi.org/10.1002/uog.3947

[27] Harada K, Ogawa M, Tanaka T. Right ventricular pre-ejection myocardial velocity and myocardial acceleration in normal fetuses assessed by Doppler tissue imaging. J Am Soc Echocardiogr. 2005; 18(4): 370-4. PMid:15846167 http://dx.doi.org/10.1016/j.echo.2004.10.017

[28] Hayashi SY, Lind BI, Seeberger A, do Nascimento MM, Lindholm BJ, Brodin LA. Analysis of mitral annulus motion measurements derived from M-mode, anatomic M-mode, tissue Doppler displacement, and 2-dimensional strain imaging. J Am Soc Echocardiogr. 2006; 19(9): 1092-101. PMid:16950463 http://dx.doi.org/10.1016/j.echo.2006.04.014

[29] Fraser AG, Payne N, Madler CF, et al. Feasibility and reproducibility of off-line tissue Doppler measurement of regional myocardial function during dobutamine stress echocardiography. Eur J Echocardiogr. 2003; 4(1): 43-53. PMid:12565062 http://dx.doi.org/10.1053/euje.4.1.43 